\title{
Innovation Management in Living Lab Projects: The Innovatrix Framework
}

\author{
Dimitri Schuurman, Aron-Levi Herregodts, \\ Annabel Georges, and Olivier Rits
}

\author{
"The man who asks a question is a fool for a minute," \\ the man who does not ask is a fool for life. \\ Confucius (551-479 BC) \\ Teacher, editor, politician, and philosopher
}

\begin{abstract}
Despite living labs being described as "orchestrators" and innovation intermediaries, there is scant literature providing concrete guidelines and tools for living lab practitioners on the topic of project-related innovation management. To address this need, we propose Innovatrix, an innovation management framework built upon existing business model and innovation management tools and frameworks and iterated based on practical experience in living lab projects. In this article, we illustrate the added value of the proposed framework through three practical case studies that lead to three propositions regarding innovation management in living lab projects. First, Innovatrix helps to scope the user involvement activities, which leads to greater efficiency and faster decision making. Second, Innovatrix forces the project owner to focus on a limited number of customer segments, which increases the speed of learning as the scarce entrepreneurial resources are dedicated to a limited number of segments. Third, Innovatrix allows practitioners to capture the iterations and pivots that were made during an innovation project, which helps to link specific outcomes with certain living lab activities.
\end{abstract}

\section{Introduction}

Living labs are complex partnerships, as they facilitate not only university-industry relationships but also relationships between large companies, SMEs, and startups, resulting in what is often referred to as public-private-people partnerships (4P's) (Westerlund \& Leminen, 2011). They are mostly initiated and funded by policy makers with national or regional policy objectives in mind (Katzy, 2012) where they function as "innovation intermediaries" to overcome the gap between $R \& D$ and market introduction. Surprisingly, there is a lack of studies that indicate the effectiveness of these organizations in realizing this ambition (Ballon et al., 2018). One of the main arguments relates to the complex nature of innovation activities and the abundance of potentially influencing factors on innovation outcomes. Thus, in order to better understand their effectiveness and realize the full potential of living labs as "innovation intermediaries", there is a need for clearer reporting of living lab activities to allow benchmarking and comparing. Moreover, Leminen and Westerlund (2017) detail a variety of innovation tools available for living lab practitioners, but they also highlight the absence of structural frameworks to apply these tools. Therefore, we believe there is a need for practitioner tools specifically designed for innovation management in living labs in order to help practitioners in the selection of living lab activities and to allow more comparisons and benchmarking between different projects and living lab organizations.

Although it has been argued that opening the innovation process through the involvement of external actors in a structural process has the potential to increase the value and sustainability of an innovation's business model (Baccarne et al., 2013), there is only a limited amount of literature available that combines living labs with business models. Rits and colleagues (2015) note that the majority of the papers in this field deals with 


\title{
Innovation Management in Living Lab Projects: The Innovatrix Framework
}

\author{
Dimitri Schuurman, Aron-Levi Herregodts, Annabel Georges, and Olivier Rits
}

the business model of living labs themselves, such as Katzy (2012), who proposes a business excellence model for running and operating a living lab in order to come to a sustainable business model for the lab itself. However, the explicit integration of business model research for the resulting innovations in living labs is very rare. Moreover, in his literature review of the most influential living lab papers, Schuurman (2015) discovered that the majority dealt with the living lab organizations. This focus feels contra-intuitive as living labs are regarded as innovation instruments and innovation intermediaries that are capable of closing the gap between research and market introduction (Almirall \& Wareham, 2011). Therefore, we would expect much more attention for the living lab project activities and practical guidelines about how to approach innovation projects in a living lab setting. The majority of the academic living lab literature focuses on explicating the defining characteristics of living labs, such as the user-centricity of the approach. The more practitioner-oriented publications tend to focus on how to set up a living lab, how to involve users, or how to carry out a living lab innovation project from start to finish (e.g., the FormIT methodology) but, to our knowledge, there are no guidelines or instruments on how to integrate business model activities in living lab projects or how to structure user interactions in line with business model development.

Therefore, in this article, we focus on this project level and look for innovation management guidelines in living labs. After a review of the living labs literature, we introduce how we iteratively constructed the Innovatrix framework, which is based on existing innovation management and business model tools and frameworks and is informed by the experience of more than 80 living lab projects. We then investigate the practical implementation of Innovatrix by means of three case studies selected from a sample of 40 living lab projects that used the framework.

\section{Innovation Management in Living Labs}

Living labs are regarded as complex phenomena where three analytical levels can be distinguished: the organizational level, the project level, and the level of individual user interactions (Schuurman, 2015). The defining elements of living labs - real-life context, multi-stakeholder, multi-method, active user co-creation and medium- to long-term duration (Schuurman et al., 2013) are situated among these three separate but interlinked layers. The multi-stakeholder characteristic especially applies to the organizational level. In this domain,
Leminen (2015) provides a very diverse overview of actor roles and management implications for living lab networks. Managing value-capture and value-creation processes within living lab organizations is crucial for their sustainability, but it is also cumbersome (Schaffers et al., 2007). This challenge also resonates with the medium- to long-term element. On the user-interactions level, end-user co-creation is regarded as the way to involve users. The literature describes various ways and strategies to facilitate the process of co-creation (e.g., Kristensson et al., 2008) and provides an overview of different user characteristics and user roles (Leminen et al., 2014; Schuurman \& De Marez, 2012) of living lab participants.

The real-life aspect and the multi-method approach are characteristics that can be linked to the project level. There is some literature on the real-life aspect and on context (e.g., Bergvall-Kåreborn et al., 2009), but we will focus in particular on the multi-method nature of living lab projects. These projects are described as a structured approach to open and user innovation (Almirall \& Wareham, 2008; Leminen et al., 2012; Schuurman et al., 2016). Therefore, living lab projects should be examined at from an innovation management perspective to define which method should be used at what time in the project and how the project is structured. However, living lab papers on methodology tend to describe a very specific methodology, which is specific for a certain living lab, or an innovation process with rather fixed elements and building blocks (e.g., BergvallKåreborn et al., 2010). The most concrete are the works of Pierson and Lievens (2005) and Schuurman and coauthors (2016) who put forward a quasi-experimental design with a pre-test, an intervention, and a post-test. Next to this, there is little to no literature that looks at innovation management in living lab projects, with the exception of some studies on "living-labs-as-a-service" (as described in the next section). This is surprising, as already in 2006, at the start of the living labs movement, Niitamo and co-authors stated that, "[i]n Living Labs there is a need to combine highly self-organized and self-managed processes with multi-disciplinary $R \& D$ and innovation management processes." Ståhlbröst (2013) also defines a living lab as "an orchestrator of open innovation processes focusing on co-creation of innovations in real-world contexts by involving multiple stakeholders with the objective to generate sustainable value for all stakeholders focusing in particular on the end users." Nonetheless, this view has not led to an abundance of papers and studies that unravel or describe this process of orchestration. 


\title{
Innovation Management in Living Lab Projects: The Innovatrix Framework
}

\author{
Dimitri Schuurman, Aron-Levi Herregodts, Annabel Georges, and Olivier Rits
}

Leminen and Westerlund (2017) presented a study that categorizes innovation tools in living labs. There they conclude that the majority of living labs do not yet have standardized tools but rather use custom-made tools, which is an indication of the immaturity of these living labs in terms of operations. However, the authors remain vague regarding the nature and applicability of these “tools". Äyväri and Jyrämä (Äyväri \& Jyrämä, 2017; Jyrämä \& Äyväri, 2015) see living labs as perfect instruments to investigate and define the value proposition of innovations and look into three existing tools and how applicable they are in a living lab context: the Value Proposition Builder (Barnes et al., 2009), the Value Proposition Canvas (Osterwalder, 2012), and the People Value Canvas (Wildevuur et al., 2013). However, they conclude that none of these tools takes into account the role of the wider context, the service ecosystem, and the role of networked actors as resource integrators. Moreover, none of the tools explicitly points out the role of enterprises as intermediaries in building invitations for value co-creation.

Because a living lab as an open ecosystem offers specific opportunities to develop new business models and tested value propositions, we believe a dedicated tool for business models and living lab activities can and should be crafted. Therefore, within this article, we present Innovatrix, a hands-on tool that takes into account specific living lab characteristics and that builds further on existing tools. Innovatrix can be used as an innovation management approach that also enables practitioners to discover the impact and outcomes of living lab interventions.

\section{Business Model Components as Innovation Management Elements}

A notable exception in the search for innovation management anchor points for living labs can be found in the scant literature on "living-labs-as-a-service". These living labs, focused on delivering specific services to external customers, play the role of innovation intermediary between entrepreneurs and end users (Ståhlbröst, 2013). Coorevits and Schuurman (2014) argue that the validation board (http://leanstartupmachine.com), from the lean startup methodology, can be used as a tool to structure living lab projects as it is focused on planning and executing user research. Rits and co-authors (2015) argue for the integration of business model research with user research in living labs. In this context, they refer to established tools linked to business modelling and technology entrepreneurship, such as the Business Model Canvas (Osterwalder \& Pigneur,
2013), the Lean Canvas (Maurya, 2012), and the Value Proposition Canvas (Osterwalder et al., 2015). D'Hauwers and colleagues (2015) proposed the iLLAB, a hypothesis-driven living lab framework incorporating both user and business model learning that based on elements from the above business model tools. They see the iLLAB tool as an aggregation of principles from Ries (2011), the Osterwalder Value Proposition Design (2015), the business model matrix of Ballon (2007), the business model canvas of Osterwalder (2010), and Porter's five forces model (1985) that is translated into a set of strategic components. They developed their own framework to gather assumptions for user research, as the input from the other frameworks remained too high-level to define and execute user research. The validation board (Ries, 2011) functioned as the main framework as it puts the customers at the core and focuses on the customer hypothesis, the problem hypothesis, and the solution hypothesis. This is also in line with the work of Wildevuur and colleagues (2013), who designed the People Value Canvas (PVC) tool to help build value propositions during user-centric service development processes. The PVC consists of nine building blocks describing the input that has to be provided to establish the value proposition. The PVC is an iteration on the Business Model Canvas and facilitates a processoriented approach, more specifically for highly iterative (and lean) innovation processes allowing for structured learning and pivoting.

However, how can we structure these elements in order to link them to the (living lab) innovation process? Herregodts and colleagues (2017) developed a framework on knowledge uncertainties in order to tackle this issue. Within these innovation uncertainties, a major distinction can be made between knowledge related to the current environment versus knowledge related to the innovation under development. While the first is closely related to problem and opportunity identification, the second is related to the formulation and evaluation of solutions. This framework is based on the metaphoric use of "states". States relate to reference points, either from the perspective of the organization or the individual (Gourville, 2005), where the existing, "current state of being", the "as is", or "status quo" is opposing "possible future states" (Alasoini, 2011). In the next sections, we will introduce the Innovatrix framework, which is based on elements from the previously discussed frameworks and tools, but which also takes into account this dichotomy between current and future state-knowledge. The Innovatrix originates from the Lean Validation Board but was iteratively modified based on hands-on application in living lab projects. 


\title{
Innovation Management in Living Lab Projects: The Innovatrix Framework
}

\author{
Dimitri Schuurman, Aron-Levi Herregodts, Annabel Georges, and Olivier Rits
}

\section{From Lean Validation Board to Innovatrix}

Innovatrix was developed within imec.livinglabs (previously iLab.o and iMinds.livinglabs), one of ENoLL's founding members and a forerunner in the network in terms of business orientation. At first, when still operating under the banner of iLab.o, the living lab projects followed a rather linear innovation methodology, quite similar to other known living labs such as Testbed Botnia (FormIT) (Almirall et al., 2012). However, as the number of projects and the organization itself started to grow, the need was felt to adopt a less linear approach that was more in line with the concrete issues the living lab customers experienced. To this end, in 2014, the Lean Validation Board was used in the projects to map and validate assumptions during the project as suggested by one of the new team members who had used the Lean Validation Board in her previous working experience. However, soon it became apparent that the validation board did not work optimally in a living lab setting, as the different elements are not really linked and there is less process involved, which made its use limited to the start of the project. Therefore, it was decided to start creating a custom-made innovation management canvas to map and validate assumptions and containing the most critical elements of a living lab innovation (see D'Hauwers et al., 2015 for a more thorough discussion on these development steps). Eventually, Innovatrix was born, consisting of eight elements informed by what we deemed from our practical experiences are most crucial for living lab innovation. To this day, 86 living lab projects have been carried out within imec.livinglabs and 40 have used Innovatrix, whereas the other 46 either used no (business model) canvas, used the lean validation board, or used a premature version of Innovatrix (see D'Hauwers et al., 2015). By having multiple customer segments, each with their own needs, etc., this canvas appeared to be more process-oriented, which made it easier to use as an innovation management tool. We see this as the biggest differentiation from the other business model canvasses, as Innovatrix starts from the user (customer segments) and assumes that different user or customer groups each have their own distinctive needs, current practices, etc. In short, it allows practitioners to link and differentiate the different elements with and for different user groups, which also allows them to capture the outcomes of living lab activities, such as co-creation activities with different users.

We now briefly introduce and discuss the criteria that compose the Innovatrix: Customer Segment, Current Practices, Needs, Value Proposition, Solution, Barriers,
Value Capture, and Key Partners (Figure 1). Below, each of these eight components is discussed in detail. We also indicate whether these elements belong to the "current state" or appear "as is" without the innovation, or if they are related to the "future state" or are yet "to be" with the innovation. For each of the criteria, we also introduce "checks" or questions that can be used to fill out the different criteria.

\section{Customer segment-Current state}

As used in the Validation Board (Ries, 2011) and the Business Model Canvas, Innovatrix starts from customer segments. However, there is room for multiple customer segments. Also, the other elements are all linked to customer segments and do not necessarily apply for all segments. This approach enables more fine-grained assumption development. In the Innovatrix framework, there is room for three customer segments (the grey areas in the framework) to cater to the need for clear focus through limited scope. The first column is used as an overarching column to map similarities between defined segments. Following the application of Innovatrix, checks can be used to gauge the need for relevant input to the Customer Segment criteria: What customer segments should be focused on? What are the key characteristics? What is the use context?

\section{Needs - Current state}

Osterwalder (2015) includes customer jobs, pains, and gains in the Value Proposition Design canvas, which is the basis for the needs identification in the Innovatrix framework. Furthermore, Ries (2011) links customer segments - customer problems and the fit with the potential solution or value proposition. Following the application of Innovatrix, checks can be used to gauge the need for relevant input into the Needs criteria: What are the needs of the customer segment? How do we prioritize these needs?

\section{Current practices - Current state}

One missing pillar in Ries (2011), Osterwalder (2010), and in Ballon (2007), is the competition and the differentiation of an SME/startup/innovator. Competition refers to the Five Market Forces of Porter (1985), which draws from the five forces model. The five forces make up the attractiveness of a market. The five forces can be defined as: 1) the degree of rivalry within the industry, 2) the threat of new entrants, 3) the threat of substitutes, 4) the bargaining power of suppliers, and 5) the bargaining power of buyers. Assessing rivalries within the industry can help identify the difficulties of entering the market. If, for example, the market consists of multiple strong players (i.e., an oligopoly market), the need 


\section{Innovation Management in Living Lab Projects: The Innovatrix Framework}

Dimitri Schuurman, Aron-Levi Herregodts, Annabel Georges, and Olivier Rits

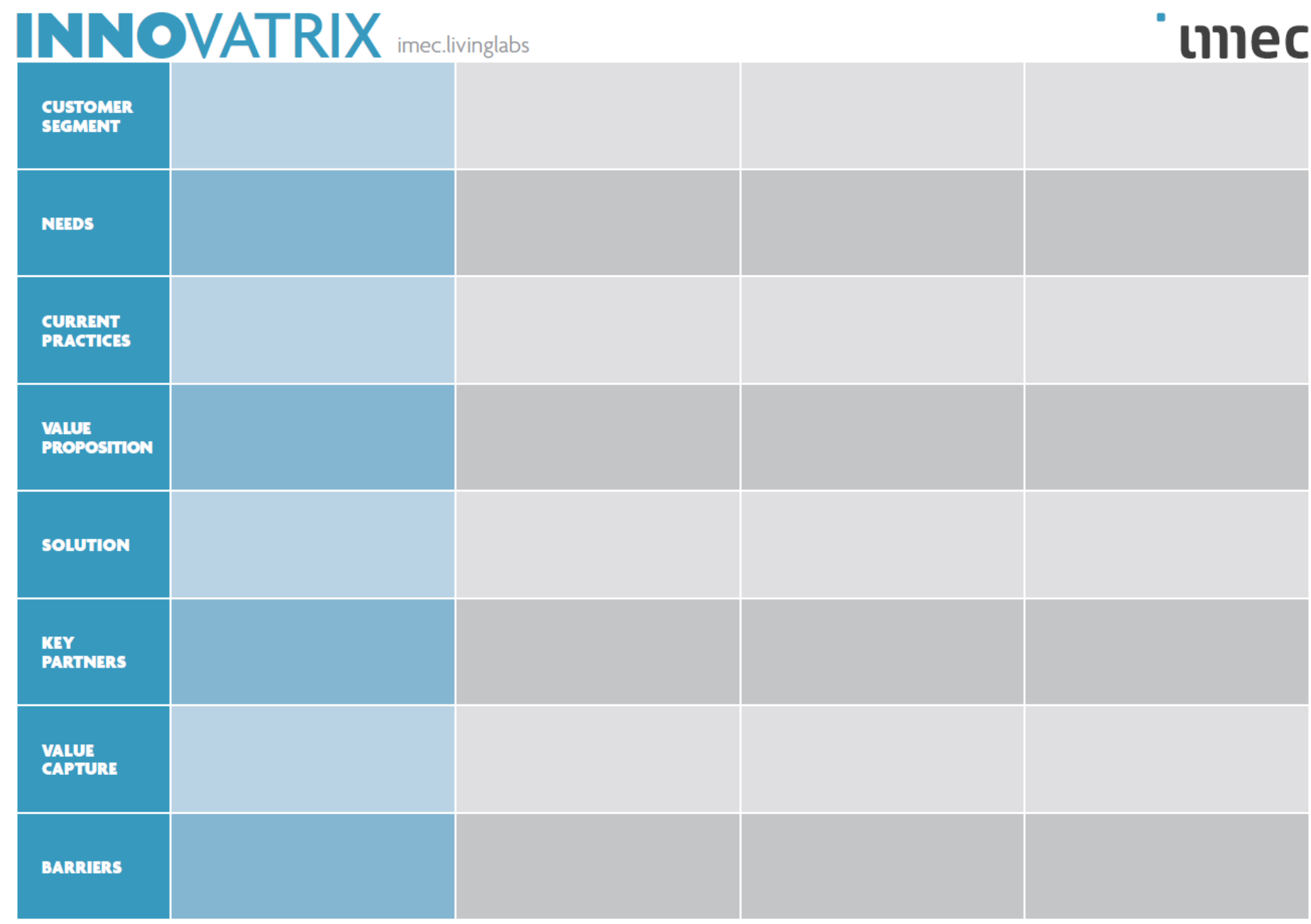

Figure 1. Innovatrix assumption and validation matrix (Available for download and printing in A0 and B0 paper sizes at http://timreview.ca/article/1225)

to diversify can lead to high barriers to entry. On the other hand, if several new entrants enter the market (i.e., monopolistic competition), it could indicate that it is an attractive market with lower barriers of entry. For some products or services, one can find possible substitutes that can serve as an alternative to the specific service or product. Following the application of Innovatrix, checks can be used to gauge the need for relevant input to the Current Practices criteria: Who are competitors, alternatives, and customers, and what is their behaviour? What are the pains and gains of these current practices?

\section{Value proposition - Current and future state}

The value proposition is covered by the Lean Matrix of Ries (2011), the Value Proposition and the Business Model Canvas of Osterwalder $(2010,2015)$, and by the
Business Model Matrix of Ballon (2007). The value proposition is the match between the needs of customer segments and how this can be solved with the solution provided by the innovator. Following the application of Innovatrix, checks can be used to gauge the need for relevant input to the Value Proposition criteria: What (measurable) impact will we create for this customer segment?

\section{Solution - Future state}

The solution refers to "the functional architecture" of Ballon (2007) in the Business Model Matrix. The functional architecture comprises the technical systems, which are composed of at least one building block (or module) governed by specific rules (or intelligence) that interwork (or not) with other technical systems through predetermined interfaces. The composition of 


\title{
Innovation Management in Living Lab Projects: The Innovatrix Framework
}

\author{
Dimitri Schuurman, Aron-Levi Herregodts, Annabel Georges, and Olivier Rits
}

the solution in the key modules and technical systems enables the researcher and the innovator to identify the unique selling point of the innovation compared to the competition. This division is less explicitly included in Osterwalder (2010), even though the difference can be significant in certain innovations. Following the application of Innovatrix, checks can be used to gauge the need for relevant input to the Solution criteria: What are the components of our (digital) solution? How do these components differ for the different customer segments?

\section{Value capture - Future state}

Ballon (2007) included the financial model in the Business Model Matrix, which described the revenue model and the revenue-sharing model. Osterwalder (2010) also takes into account the revenue model, where the pricing level and the pricing model are mentioned. Therefore, we opted to utilize the definition of "value capture", which comprises the pricing model and the pricing level, and in cases where revenue sharing is applicable, this section can be utilized. The application of the Innovatrix framework in different projects shows that partners can face difficulties identifying their pricing model and pricing level, and thus this needs to be included in the framework. Value capturing has an important link with how pressing the customer need is and to the associated value the partner promises to deliver. Following the application of Innovatrix, checks can be used to gauge the need for relevant input to the Value Capture criteria: What value (monetary and nonmonetary) do we receive in return? What price should we set (and how)?

\section{Key partners - Future state}

The value network definition is an alternative to the broad, market-based approach of the Business Model Matrix of Ballon (2007). In the value network analysis, however, the applicability is more adapted to innovations in the form of partnerships required to deliver the innovation to the customers and with whom do innovators need to collaborate. Following the application of Innovatrix, checks can be used to gauge the need for relevant input to the Key Partners criteria: Who are our key partners? How should we interact with stakeholders?

\section{Barriers - Future state}

According to Steinkühler and colleagues (2014), self-justification is the most empirically supported explanation for escalation of commitment, the "...tendency to become locked-in to a course of action, throwing good money after bad or committing new resources to a losing course of action" (Staw, 1981). Therefore,
Steinkühler and colleagues (2014) argue that self-justification cannot be totally avoided but for de-escalation of the commitments, the search for disconfirming evidence can help. Therefore, it was decided to explicitly include "barriers" as an element to look for this disconfirming evidence. This forces the practitioner to play the role of "devil's advocate". Following the application of Innovatrix, checks can be used to gauge the need for relevant input to the Barriers criteria: What are the barriers to adoption, usage, and/or market entry?

\section{Innovatrix Put into Practice: From Workshop to Innovation Management Process}

In practice, the Innovatrix has two uses: 1) as an innovation framework in a hands-on workshop session and 2) as an innovation management process.

First, as an innovation framework, the Innovatrix is used at the start of an innovation project, for example during a kick-off workshop. The most important roles in such a workshop are the trained Innovatrix facilitator and the innovator (or the innovator's team). The workshop starts with an innovation pitch provided by the innovator. After this pitch, the eight distinctive Innovatrix criteria - as described above - are "filled" with relevant input from the innovator. Here, the facilitator plays an important role in the gathering of all relevant input through very specific probing questions in the form of "Innovatrix checks". The gathered input is then awarded one of initially two possible statuses based on the nature and the strength of the input: either assumption (the input has not yet been validated and is thus hypothesized by the innovator) or validated assumption (the input has already been validated through previous activities). Depending on the assumption status, the input is mapped on different-coloured post-its: yellow (assumptions) or green (validated assumptions). The outcome of an Innovatrix workshop is the mapping of assumptions and validated assumptions, followed by marking the most important assumptions as "key uncertainties". Subsequent research activities should focus on these key uncertainties.

Second, the Innovatrix is used in support of the innovation management process. Here, the Innovatrix framework is used as the starting point of a living lab innovation project. The outcome of the Innovatrix workshop, the list of key uncertainties, is then translated into testable assumptions and is matched with appropriate research and innovation activities. Research and innovation activities are then carried out. In the next Innovatrix workshop, the Innovatrix update, the focus is placed 


\title{
Innovation Management in Living Lab Projects: The Innovatrix Framework
}

\author{
Dimitri Schuurman, Aron-Levi Herregodts, Annabel Georges, and Olivier Rits
}

on the key uncertainties that were object of research and innovation activities. Here, the assumption status is under debate based on the outputs of the research and innovation activities. In an Innovatrix update, the status of an assumption can be changed in dialogue with the entrepreneur with following possible statuses: assumption (the research has not been validated), validated assumption (the input was validated), new insight (new information arose from the research and innovation activities), and invalidated (the assumption was not supported). The Innovatrix is thus used in support of the innovation management process through the mapping and changing of assumption statuses in a structured dialogue with the innovator throughout the entire living lab innovation project. This process is repeated until the end of the living lab project.

\section{Case Illustrations}

In order to illustrate the practical application and value of Innovatrix, we looked for illustrative case studies (Yin, 2017) in our sample of 40 living lab innovation projects that made use of the Innovatrix out of the 86 living lab projects that have been carried out by imec.livinglabs since its inception (see also Schuurman \& Protic, 2018). For an idea of some of the projects and of the bigger sample, see Schuurman (2015) and Schuurman and co-authors (2016). Common to all the selected projects is the presence of a single entrepreneur or entrepreneurial organization that can be considered as "innovation owner" and the use of at least two different user co-creation or user interaction methods during the project. For each project, a separate online archive is created containing all project deliverables and researcher notes of all customer meetings, including the Innovatrix workshops (where the Innovatrix canvas is filled out together with the entrepreneurial team). Based on these notes and on the project outcomes, we selected three case studies where Innovatrix was used and, in our estimation, provided specific value to the innovation project.

\section{Motosmarty}

This project was focusd on a mobile application that detected the driving behaviour of young people in order to give feedback and assess their risk profile. In term of end-user focus, there were no issues as the target population were young people and students. Co-creation sessions, surveys, and user tests were performed to iterate the application. However, in terms of customer segment for the generated data of the application, there was no focus at all. Here, Innovatrix was used to explicate all knowledge and assumptions regarding 17 cus- tomer segments (e.g., insurance companies, the government, research institutes). This led to discussions inside the team and made them realize that focus was needed, otherwise they would burn all their resources without finding a paying businesss-to-business (B2B) customer. The application is now on the market as Viva Drive (vivadrive.io), and it focuses on insurance companies and large companies that want to monitor their own car fleets. By using Innovatrix, internal team differences were made explicit and could be resolved, and a clear and motivated focus could be facilitated.

\section{Spott}

This living lab project focused on Spott (spott.ai), a new way for users to use their smartphones to recognize, like, share, and buy products they saw during a television show or commercial including, for example, the types of clothing worn by the actors or the objects in the scenes. The Innovatrix workshop at the start of the project indicated three types of end-user segments and the television stations. In terms of value capture, the assumption was that an affiliate marketing fee would be the main source of income for Spott. However, based on the co-creation sessions and field trials with the application, it appeared that the "buying" of items recognized during the television show was not that common, but that more adept viewers felt more connected to the television content itself as they received more information on the objects that were used or worn by their favorite characters. This newly discovered evidence made Spott delete one of the end-user segments, the one that was focused on general viewers buying products. Instead, they focused on potential revenue from television stations paying to use the application for their shows. It was felt that this higher level of engagement with viewers, especially frequent viewers, would attract advertisers and increase their willingness to pay. By visualizing the different customer segments and putting the evidence of the research activities in one matrix, decisions could be made by the innovation team and the business model itself could be iterated. In this project, Innovatrix brought scope, identified unexpected outcomes, and enabled the team to focus on a limited number of segments while taking into account the main sources of revenue. At the moment, Spott has already been launched in multiple countries worldwide and is growing rapidly.

\section{Lab Box}

Lab Box is the organization behind Pikaway (pikaway.com), a multi-modal transport application that helps users plan and book trips without being restricted to one or only a few means of transport. At the starting workshop, 


\title{
Innovation Management in Living Lab Projects: The Innovatrix Framework
}

\author{
Dimitri Schuurman, Aron-Levi Herregodts, Annabel Georges, and Olivier Rits
}

it appeared that the three envisioned customer segments were still rather high level and in need of specification. To tackle this, we performed a segmentation survey and subsequently conducted a field trial with representatives of the user segments. This enabled the team to create persona, which provided focus for the developers to prioritize their development backlog. Moreover, one of the key assumptions captured during the first workshop, the need for a one-stop shop application, could be iteratively validated by capturing the frustrations with the current practices in the segmentation survey and co-creation session, but this was also expressed in the field trial so this was also reflected in the future state (i.e., the Solutions element). During the project, Innovatrix was used as a reporting tool for the different research activities. The tool provided crucial evidence that was used by the coding team that was developing the application in parallel with the living lab project. Moreover, the development team also put forward key questions or assumptions to be researched in subsequent user activities. This approach ensured efficient alignment of research by the living labs team and development by the Lab Box team. At the end of the project, the team from Lab Box asked for the main takeaways and their recommended next steps based on the project. By going through the Innovatrix framework and the modifications step by step, we could easily extract the main learnings and key elements to work on before the market launch. At this moment, Pikaway is available in the app store and a launch in the Play Store is planned for the near future.

\section{Discussion and Conclusion}

Although living labs are regarded as orchestrators, which hints at an innovation management approach, there is a lack of literature and studies that further explicate this role of the process. Rather, living labs are described and studied in terms of defining characteristics (such as real-life experimentation, active user co-creation, and public-private-people partnership), but what is left untouched is how these elements should be managed and utilized according to the needs and characteristics of a specific innovation project. For living labs to take the next step in becoming mature and established innovation organizations, we feel that this innovation management role should be further elaborated and that this is even crucial given the inherent complexity of living labs. The three-layered model by Schuurman (2015) provides a useful framework to anchor these elaborations. In our literature review, we noticed that the largest gap in terms of the orchestration role in living labs is situated on the project level.
Therefore, within this article, we focused on the question of how innovation management in living lab projects can be facilitated and supported by tools or frameworks.

As a result, we presented the Innovatrix framework, which consists of eight elements derived from existing business model tools and frameworks. The specific characteristic of the framework is that all of its elements should be specified for each customer segment that is identified. Moreover, Innovatrix also clearly distinguishes between the current state elements (the top three) and the future state elements (the bottom four), which gives it a more dynamic, process-like feeling.

Based on a sample of 86 living lab projects, we chose three case studies of projects from the sample that used innovatrix to illustrate how we derived three propositions regarding the use and implications of the Innovatrix framework for Living Lab practitioners.

First, Innovatrix helps to scope the user involvement activities, as it clearly explicates assumptions related to the different customer segments, and it also enables practitioners to indicate which assumptions are key for taking the next steps in the project. This leads to a more efficient use of resources and facilitates the selection of representative users for the given customer segments. It also guides the choice of method to validate the assumption, as seen in the Lab Box case, for example.

Second, Innovatrix forces the project owner to focus on a limited number of customer segments, as there is only room for three to four segments maximum. If there are more segments, the elements of the Innovatrix help to choose between different segments in terms of focus. This approach increases the efficient use of the scarce entrepreneurial resources and helps decision making for the innovation teams, as seen in the Motosmarty case, for example.

Third, Innovatrix allows practitioners to iterate the business model based on the consistency of the Innovatrix elements and to capture the iterations and pivots that were made during an innovation project, as seen in the Spott case, for example.

This approach allows specific outcomes to be linked with certain living lab activities, which has been previously identified rather problematic (see Ballon et al., 2018). Innovatrix serves as a visual summary of key elements and assumptions regarding an innovation project from the viewpoint of the end user. By capturing 


\section{Innovation Management in Living Lab Projects: The Innovatrix Framework}

Dimitri Schuurman, Aron-Levi Herregodts, Annabel Georges, and Olivier Rits

snapshots of the Innovatrix framework before and after a research activity, the modifications and alterations become apparent. To this end, a digital version of Innovatrix is being built that enables practitioners to fill out Innovatrix digitally and keeps track of all changes during a project. Moreover, Innovatrix is also an interesting tool to facilitate the discussion between living lab researchers and the project owners.

To further explore and validate these propositions, further research and more cases are needed to assess the value of Innovatrix. Also, Innovatrix represent a specific view on innovation management and living lab activities but might have broader applicability. It has been used in a "living-labs-as-a-service" context, but it might be applicable in other contexts as well. We encourage uses and tests in other contexts, other types of projects, and other organizations in order to increase the knowledge on innovation management in a living lab context and to help in building a more structural, encompassing Innovatrix for all kinds of living lab projects and activities. We feel that this would increase both the impact and position of living labs as innovation intermediaries.

\section{About the Authors}

Dimitri Schuurman is the Team Lead of the Business model and User Research Team at imec.livinglabs. He holds a PhD and a Master's degree in Communication Sciences from Ghent University in Belgium. Together with his imec colleagues, Dimitri developed a specific living lab offering targeted at entrepreneurs in which he has managed over 100 innovation projects. He is also active in the International Society for Professional Innovation Management (ISPIM) and in the European Network of Living Labs (ENoLL) as a living labs specialist. His main interests and research topics are situated in the domains of open innovation, user innovation, and innovation management.

Aron-Levi Herregodts is an Innovation Manager at imec.livinglabs. He holds Master's degrees in Communication Sciences (2013) and Complementary Business Economics (2014). He is the imec.livinglabs product owner of Innovatrix and applies this methodological approach on a day-to-day basis to a widevariety of innovation projects.

Annabel Georges is an Innovation Manager at imec.livinglabs. Within this "living-lab-as-a-service" she conducts user research to structurally support innovation development for SMEs. Next to this, she is also involved in several smart city projects. Her main research topics are drop-out and user engagement within field tests and working on the processes of current living lab practices. Annabel holds a Master's degree in Communication Sciences with a specialization in New Media and Society from Ghent University.

Olivier Rits is Program Manager at imec.livinglabs. He holds a Master's degree in Applied Physics (Engineering) from Ghent University in Belgium. Previously, Olivier worked as a business developer for Alcatel-Lucent, where he was involved with many different technologies, and for the research group SMIT, where he was responsible for the business modelling practice in the context of SME living lab innovation projects. 


\section{Innovation Management in Living Lab Projects: The Innovatrix Framework}

\section{Dimitri Schuurman, Aron-Levi Herregodts, Annabel Georges, and Olivier Rits}

\section{References}

Almirall, E., \& Wareham, J. 2008. Living Labs and Open Innovation: Roles and Applicability. The Electronic Journal for Virtual Organizations and Networks, 10(3): 21-46.

Almirall, E., \& Wareham, J. 2011. Living Labs: Arbiters of Mid- and Ground-Level Innovation. Technology Analysis \& Strategic Management, 23(1): 87-102.

https://doi.org/10.1080/09537325.2011.537110

Almirall, E., Lee, M., \& Wareham, J. 2012. Mapping Living Labs in the Landscape of Innovation Methodologies. Technology Innovation Management Review, 2(9): 12-18. http://doi.org/10.22215/timreview/603

Äyväri, A., \& Jyrämä, A. 2017. Rethinking Value Proposition Tools for Living Labs. Journal of Service Theory and Practice, 27(5): 1024-1039.

https://doi.org/10.1108/JSTP-09-2015-0205

Baccarne, B., Logghe, S., Veeckman, C., \& Schuurman, D. 2013. Why Collaborate in Long-Term Innovation Research? An Exploration of User Motivations in Living Labs. Paper presented at the 4th European Network of Living Labs (ENoLL) Living Lab Summer School 2013.

Ballon, P. 2007. Business Modelling Revisited: The Configuration of Control and Value. info, 9(5): 6-19.

https://doi.org/10.1108/14636690710816417

Ballon, P., Van Hoed, M., \& Schuurman, D. 2018. The Effectiveness of Involving Users in Digital Innovation: Measuring the Impact of Living Labs. Telematics and Informatics, 35(5): 1201-1214. https://doi.org/10.1016/j.tele.2018.02.003

Bergvall-Kåreborn, B., Ihlström Eriksson, C. Ståhlbröst, A., \& Svensson, J. 2009. A Milieu for Innovation: Defining Living Labs. In Proceedings of the 2nd ISPIM Innovation Symposium, New York, December 6-9.

Bergvall-Kåreborn, B., Howcroft, D., Ståhlbröst, A., \& Wikman, A. M. 2010. Participation in Living Lab: Designing Systems with Users. In J. Pries-Heje, J. Venable, D. Bunker, N. L. Russo, \& J. I. DeGross (Eds), Human Benefit through the Diffusion of Information Systems Design Science Research. TDIT 2010. IFIP Advances in Information and Communication Technology, 318. Berlin: Springer.

https://doi.org/10.1007/978-3-642-12113-5_19

Blank, S. 2006. The Four Steps to the Epiphany. Foster City, CA: Cafepress.com.

Blank, S. 2013. Why the Lean Start-Up Changes Everything. Harvard Business Review, 91(5): 63-72.

CB Insights. 2018. 253 Startup Failure Post-Mortems. CB Insights. Accessed July 1, 2018:

https://www.cbinsights.com/research/startup-failure-postmortem/

Coorevits, L., \& Schuurman, D. 2014. Hypothesis Driven Innovation: Lean, Live and Validate. In Proceedings of the XXV International Society for Professional Innovation Management (ISPIM) Innovation Conference.

D'Hauwers, R., Rits, O., \& Schuurman, D. 2015. A Hypothesis Driven Tool to Structurally Embed User and Business Model Research within Living Lab Innovation Tracks. Paper presented at the 2015 European Network of Living Labs (ENoLL) Open Living Lab Days.
Gage, D. 2012. The Venture Capital Secret: 3 Out of 4 Start-Ups Fail. The Wall Street Journal, September 29, 2012. Accessed March 1, 2019:

https://www.wsj.com/articles/SB1000087239639044372020457800 4980476429190

Gourville, J. T. 2005. The Curse of Innovation: A Theory of Why Innovative New Products Fail in the Marketplace. HBS Marketing Research Paper No. 05-06. Boston, MA: Harvard Business School (HBS).

https://dx.doi.org/10.2139/ssrn.777644

Herregodts, A. L., Baccarne, B., Conradie, P., \& Schuurman, D. 2017. Managing Innovation Uncertainties: A User-Oriented Knowledge Typology. In Proceedings of the 2017 International Society for Professional Innovation Management (ISPIM) Innovation Symposium.

Jyrämä, A., \& Äyväri, A. 2015. Art Encountering Society; Identifying the Skills. Paper presented at the 13th International Conference on Arts and Cultural Management (AIMAC), Aix-en-Provence and Marseille, France, June 28 - July 2, 2015.

Katzy, B. 2012. Designing Viable Business Models for Living Labs. Technology Innovation Management Review, 2(9): 19-24.

http://doi.org/10.22215/timreview/604

Kristensson, P., Matthing, J., \& Johansson, N. 2008. Key Strategies for the Successful Involvement of Customers in the Co-Creation of New Technology-Based Services. International Journal of Service Industry Management, 19(4): 474-491. http://dx.doi.org/10.1108/09564230810891914

Leminen, S., Westerlund, M., \& Nyström, A.-G. 2014. On Becoming Creative Consumers - User Roles in Living Labs Networks. International Journal of Technology Marketing, 9(1): 33-52. http://dx.doi.org/10.1504/IJTMKT.2014.058082

Leminen, S. 2015. Living Labs as Open Innovation Networks Networks, Roles and Innovation Outcomes. Doctoral dissertation. Helsinki, Finland: Aalto University.

Leminen, S., \& Westerlund, M. 2017. Categorization of Innovation Tools in Living Labs. Technology Innovation Management Review, 7(1): 15-25. http://doi.org/10.22215/timreview/1046

Lovallo, D., \& Kahneman, D. 2003. Delusions of Success. Harvard Business Review, 81(7): 56-63.

Maurya, A. 2012. Running Lean: Iterate from Plan A to a Plan That Works. Sebastopol, CA: O'Reilly

Osterwalder, A. \& Pigneur, Y. 2013. Business Model Generation: A Handbook for Visionaries, Game Changers, and Challengers. Chichester, UK: John Wiley \& Sons.

Osterwalder, A., Pigneur, Y., Bernarda, G., \& Smith, A. 2015. Value Proposition Design: How to Create Products and Services Customers Want. Chichester, UK: John Wiley \& Sons.

Ries, E. 2011. The Lean Startup: How Constant Innovation Creates Radically Successful Businesses. New York: Crown Business.

Rits, O., Schuurman, D., \& Ballon, P. 2015. Exploring the Benefits of Integrating Business Model Research within Living Lab Projects. Technology Innovation Management Review, 5(12): 19-27. https://timreview.ca/article/949 


\section{Innovation Management in Living Lab Projects: The Innovatrix Framework \\ Dimitri Schuurman, Aron-Levi Herregodts, Annabel Georges, and Olivier Rits}

Schaffers, H., Cordoba, M. C., Hongisto, P., Kallai, T., Merz C., \& van Rensburg, J. 2007. Exploring Business Models for Open Innovation in Rural Living Labs. Paper presented at the 13th International Conference on Concurrent Enterprising (ICE), Sophia-Antipolis, France.

Schuurman, D., \& De Marez, L. 2012. Structuring User Involvement in Panel-Based Living Labs. Technology Innovation Management Review, 2(9): 31-38.

http://doi.org/10.22215/timreview/606

Schuurman, D., De Marez, L., \& Ballon, P. 2013. Open Innovation Processes in Living Lab Innovation Systems: Insights from the LeYLab. Technology Innovation Management Review, 3(11): 28-36. http://doi.org/10.22215/timreview/743

Schuurman, D. 2015. Bridging the Gap between Open and User Innovation? Exploring the Value of Living Labs as a Means to Structure User Contribution and Manage Distributed Innovation. Doctoral dissertation. Ghent University and Vrije Universiteit Brussel VUB.

Schuurman, D., \& Protic, S. M. 2018. Living Labs versus Lean Startups: An Empirical Investigation. Technology Innovation Management Review, 8(12): 7-16.

http://doi.org/10.22215/timreview/1201

Ståhlbröst, A. 2013. A Living Lab as a Service: Creating Value for Micro-enterprises through Collaboration and Innovation. Technology Innovation Management Review, 3(11): 37-42. http://doi.org/10.22215/timreview/744

Staw, B. M. 1981. The Escalation of Commitment to a Course of Action. Academy of Management Review, 6(4): 577-587. https://doi.org/10.5465/amr.1981.4285694

Steinkühler, D., Mahlendorf, M. D., \& Brettel, M. 2014. How Selfjustification Indirectly Drives Escalation of Commitment - A Motivational Perspective. Schmalenbach Business Review, 66(2): 191-222.

Wildevuur, S., van Dijk, D., Hammer-Jacobsen, T., Bjerre, M., Äyväri, A., \& Lund, J. 2013. Connect - Design for an Empathic Society. Amsterdam: BIS Publishers.

Yin, R. K. 2009. Case Study Research: Design and Methods. Thousand Oaks, California: SAGE Publications, Inc.
Citation: Schuurman, D., Herregodts, A.-L., Georges, A., \& Rits, O. 2019. Innovation Management in Living Lab Projects: The Innovatrix Framework. Technology Innovation Management Review, 9(3): 63-73. http://doi.org/10.22215/timreview/1225

Keywords: living labs, innovation management, business modelling, user research, assumption, validation, testing 


\section{Academic Affiliations and Funding Acknowledgements}
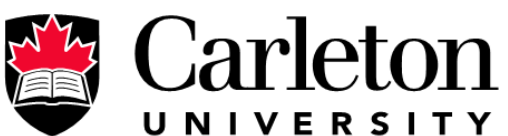

U N I V E R S I T Y

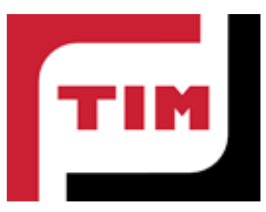

Technology Innovation Management (TIM; timprogram.ca) is an international master's level program at Carleton University in Ottawa, Canada. It leads to a Master of Applied Science (M.A.Sc.) degree, a Master of Engineering (M.Eng.) degree, or a Master of Entrepreneurship (M.Ent.) degree. The objective of this program is to train aspiring entrepreneurs on creating wealth at the early stages of company or opportunity lifecycles.

- The TIM Review is published in association with and receives partial funding from the TIM program. 